\section{Defining obesity hypoventilation syndrome}

The definition of obesity hypoventilation syndrome (OHS) proposed by Hart et al ${ }^{1}$ raises two questions that we have tried to answer briefly in this letter.

First, previous definitions of OHS included obstructive sleep apnoea (OSA); Hart et al have excluded it. Why? OSA is present in most patients with OHS and is partly responsible for the hypercapnia. ${ }^{2} \mathrm{We}$ believe that it is useful to include it in the definition or classification of the condition in a manner similar to narcolepsy: OHS with OSA and OHS without OSA, as in narcolepsy with cataplexy and narcolepsy without cataplexy. Such classification has mechanistic and therapeutic implications. ${ }^{3} 4$

Second, are high bicarbonate and base excess enough to establish the presence of chronic respiratory acidosis? For detecting OHS, a bicarbonate level cut-off of $27 \mathrm{mmol} / \mathrm{L}$ has a sensitivity close to $90 \%$, but a specificity as low as 50\%. ${ }^{5}$ Thus, a bicarbonate level less than $27 \mathrm{mmol} / \mathrm{L}$ excludes OHS, whereas a higher level only suggests it and must be followed by measurement of arterial blood gases.

Additionally, a high bicarbonate level indicates a metabolic alkalosis but does not differentiate a primary from a compensatory one. Because obese patients are frequently hyperaldosteronemic and are often on diuretics, corticosteroids, or both, they are prone to develop primary metabolic alkalosis that triggers mild compensatory hypercapnia. ${ }^{7}$ Thus, when OHS is suspected but the $\mathrm{pH}$ and the partial pressure of carbon dioxide are found to be slightly elevated, the physician should avoid attributing this result to hyperventilation from the pain of an arterial puncture and should consider interpreting it as a primary metabolic alkalosis. ${ }^{9}$

In summary, OSA and careful interpretation of arterial blood gas are critical for the definition of OHS. Obesity and elevated bicarbonate are merely triggers to look for it.

\section{Aiman Tulaimat, Stephen Littleton}

Department of Pulmonary, Critical Care, and Sleep Medicine, John H Stroger Hospital of Cook County, Chicago, Illinois, USA
Correspondence to Dr Aiman Tulaimat, Department of Pulmonary, Critical Care, and Sleep Medicine, John H Stroger Hospital of Cook County, 1900 West Polk Street, room 1404, Chicago, IL 60612, USA; atulaimat@cookcountyhhs.org

Contributors AT: conception and writing. SL: conception and writing.

Competing interests None.

Provenance and peer review Not commissioned; internally peer reviewed.

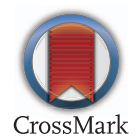

To cite Tulaimat A, Littleton S. Thorax 2014:69:491.

Received 11 December 2013

Accepted 12 December 2013

Published Online First 3 January 2014

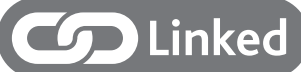

http://dx.doi.org/10.1136/thoraxjnl-2013-204298

Thorax 2014:69:491.

doi:10.1136/thoraxjnl-2013-204992

\section{REFERENCES}

1 Hart N, Mandal S, Manuel A, et al. Obesity hypoventilation syndrome: does the current definition need revisiting? Thorax 2014;69:83-4.

2 Mokhlesi B, Tulaimat A. Recent advances in obesity hypoventilation syndrome. Chest 2007;132:1322-36.

3 Norman RG, Goldring RM, Clain JM, et al. Transition from acute to chronic hypercapnia in patients with periodic breathing: predictions from a computer model. J Appl Physiol 2006;100:1733-41.

4 Mokhlesi B, Tulaimat A, Evans AT, et al. Impact of adherence with positive airway pressure therapy on hypercapnia in obstructive sleep apnea. J Clin Sleep Med 2006;2:57-62.

5 Macavei VM, Spurling KJ, Loft J, et al. Diagnostic predictors of obesity-hypoventilation syndrome in patients suspected of having sleep disordered breathing. J Clin Sleep Med 2013;9:879-84.

6 Mokhlesi B, Tulaimat A, Faibussowitsch I, et al. Obesity hypoventilation syndrome: prevalence and predictors in patients with obstructive sleep apnea. Sleep Breath 2007;11:117-24.

7 Schrier RW, Masoumi A, Elhassan E. Aldosterone: role in edematous disorders, hypertension, chronic renal failure, and metabolic syndrome. Clin J Am Soc Nephrol 2010;5:1132-40.

8 Galla JH. Metabolic alkalosis. J Am Soc Nephro 2000;11:369-75. http://jasn.asnjournals.org/content/ 11/2/369.short (accessed 8 Nov 2013).

9 Morgan EJ, Baidwan B, Petty TL, et al. The effects of unanesthetized arterial puncture on $\mathrm{PCO} 2$ and $\mathrm{pH}$. Am Rev Respir Dis 1979;120:795-8. 